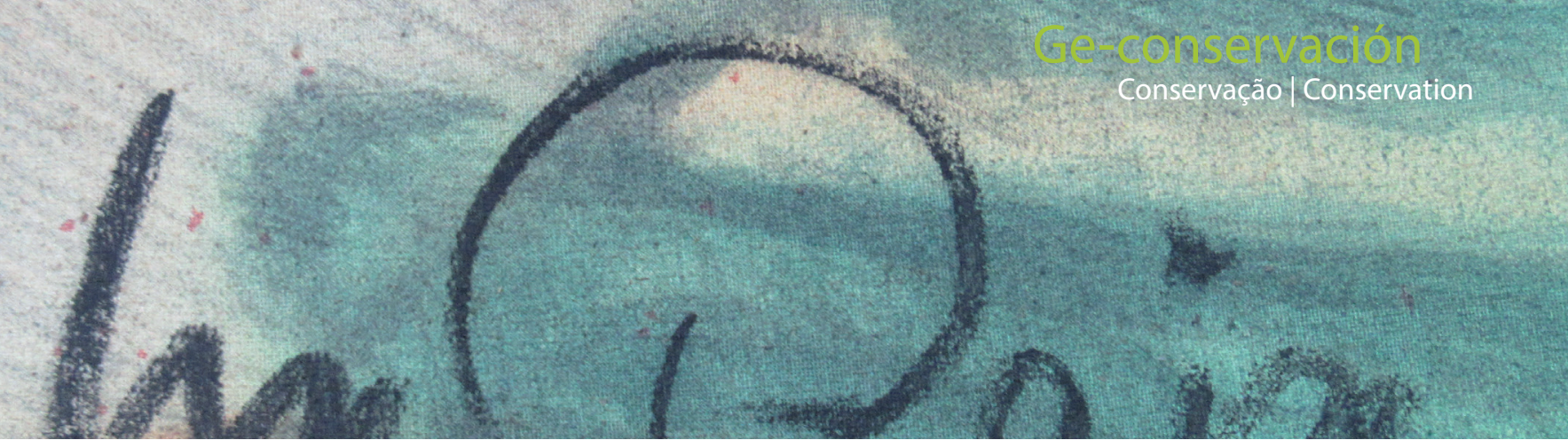

\title{
Pintar la mar (1984) de Manuel Boix: evaluación de riesgos y viabilidad de la compleja eliminación del barniz envejecido
}

\author{
Mayte Pastor Valls, Livio Ferrazza, Maite Ciganda Azcarate
}

\begin{abstract}
Resumen: El presente artículo aborda los estudios realizados a fin de evaluar los riesgos y la viabilidad de la compleja intervención de limpieza de la obra Pintar la mar de Manuel Boix, la cual se centra en la retirada del barniz superficial. El envejecimiento de esta capa de tipo alquídico directamente aplicada a compresor sobre el soporte textil y las zonas de dibujo producía un impacto cromático negativo en opinión del artista debido a su tono amarillo-anaranjado. Su retirada, sin producir cercos en el tejido y dañar las áreas de color planteaba un verdadero reto. Además de la realización de entrevistas y la caracterización previa de los materiales constitutivos de la obra mediante técnicas microscópicas, espectroscópicas y cromatográficas, fue necesario desarrollar un sistema de testado con pruebas in vitro e in vivo. Entre los sistemas evaluados destaca el uso de medios abrasivos físico-mecánicos, solvent surfactant gels, geles siliconados de solventes, así como nanogeles químicos, siendo estos dos últimos los que aportaron mejores resultados. La estimación del riesgo y efectividad de las pruebas tuvo en cuenta los cambios morfológicos, de color y brillo, así como la eficacia de la retirada del barniz, la conservación del color y la presencia de residuos. De ahí que se trazara un protocolo de evaluación mediante el uso de distintas técnicas de análisis morfológico (video-microscopio y SEM) y espectroscópico (EDX y FTIR-ATR), colorimetría y medición del brillo especular.
\end{abstract}

Palabras clave: pintura contemporánea, limpieza, Solvent Surfactant Gel, Velvesil Plus ${ }^{\circledR}$, Nanorestore ${ }^{\circledR}$ Gel and Cleaning ${ }^{\oplus}$, barniz alquídico

\section{Pintar la mar (1984) by Manuel Boix: evaluation and feasibility assessment of the complex aged varnish removal}

\begin{abstract}
This article focuses on the studies carried out in order to evaluate the risks and the feasibility of the complex cleaning intervention of Manuel Boix's painting Pintar la mar. According to the artist, the aging of the alkyd varnish directly applied by compression on canvas and the drawing areas, impacted negatively on the chromatic perception of the painting due to the yellow-orange shade. Removing the yellow-orange shade layer without creating fabric rims and damaging the color areas was a challenging issue. In addition to conducting interviews and characterizing constituent materials using microscopic, spectroscopic and chromatographic techniques, it was necessary to develop a testing system with in vitro and in vivo tests. Among the evaluated systems, the use of physical-mechanical abrasive media, solvent surfactant gels, silicone solvent gels, as well as chemical nanogels, the latter two provided the best results. The estimation of risk and effectiveness of the tests took into account the morphological changes, color and gloss, as well as the efficacy of the varnish removal procedure, the color conservation and the presence of residues. Hence, an evaluation protocol was drawn up using different morphological (video-microscope and SEM) and spectroscopic (EDX and FTIR-ATR) techniques, colorimetry and specular brightness measurement.
\end{abstract}

Keyword: contemporary paint, cleaning, Solvent Surfactant Gel, Velvesil Plus ${ }^{\oplus}$, Nanorestore ${ }^{\circledR}$ Gel and Cleaning ${ }^{\oplus}$, alkyd varnish

\section{Pintar la mar (1984) de Manuel Boix: avaliação dos riscos e viabilidade da remoção complexa do verniz envelhecido}

Resumo: Este artigo aborda os estudos realizados com o objetivo de avaliar os riscos e a viabilidade da complexa intervenção de limpeza da pintura Pintar la mar de Manuel Boix, que incide na remoção do verniz superficial. O envelhecimento desta camada do tipo alquídico, aplicada a compressor diretamente sobre o suporte têxtil e nas áreas de desenho, produziu, na opinião do artista, um impacto cromático negativo devido ao seu tom amarelo alaranjado. A sua remoção, sem criar anéis no tecido e danificar as zonas coloridas, constituiu um verdadeiro desafio. Além da realização de entrevistas e da prévia caracterização dos materiais constituintes do obra, mediante técnicas microscópicas, espectroscópicas e cromatográficas, foi necessário o desenvolvimento de um sistema de testes com ensaios in vitro e in vivo. Dos sistemas avaliados, destacou-se o uso de meios abrasivos físico-mecânicos, géis de surfactantes e solventes, géis siliconados de solventes, bem como nanogéis químicos, sendo os dois últimos os que proporcionaram os melhores resultados. A estimativa de risco 
e eficácia dos ensaios teve em consideração as alterações morfológicas, de cor e brilho, assim como a eficácia na remoção do verniz, a conservação da cor e a presença de resíduos. Foi elaborado um protocolo de avaliação mediante a utilização de distintas técnicas de análise morfológica (vídeo-microscópio e SEM) e espectroscópica (EDX e FTIR-ATR), colorimetria e medição de brilho especular.

Palavras-chave: pintura contemporanea, limpeza, Gel de surfatantes e solventes, Velvesil Plus ${ }^{\oplus}$, Nanorestore ${ }^{\oplus}$ Gel e Cleaning ${ }^{\oplus}$, verniz alquídico

\section{Introducción}

Pintar la mar es un díptico de $200 \times 300 \mathrm{~cm}$ realizado por el artista valenciano Manuel Boix en 1984 con técnica mixta sobre tejido de algodón "Rosete Imperial" y sendos bastidores artesanales de madera de pino. La capa pictórica está realizada con distintas técnicas de dibujo directamente sobre la tela, previamente encolada con cola de conejo, la cual forma parte del estrato de color. Así, con gran maestría y dominio de la técnica, Boix empleó diversos materiales como lápiz, carboncillo, lápices grasos, tinta china Pelikan ${ }^{\circledR}$ (ej. líneas de dibujo en la gaviota), junto a la aplicación de pintura al óleo más o menos diluida, mezclada con barniz alquídico y esencia de trementina. Las transiciones de color fueron resueltas mediante el uso de aerógrafo, carboncillo, goma de borrar y lápiz de fibra de vidrio. Sobre este estrato, tal y como solía realizar en obras de esta época, aplicó una capa generosa de barniz Titanlux ${ }^{\circledR}$ (Industrias Titán S.A.U.) a compresor. Este fue también diluido en esencia de trementina ${ }^{[1]}$. Aunque se decantaba por los acabados brillantes, en ocasiones podía añadir barniz mate y grandes cantidades de aguarrás, realizando barnizados muy intensos que eran modificados con hisopos embebidos en solvente como medio de incrementar el brillo y jugar con los acabados y volúmenes [figura 1].

El envejecimiento del barniz alquídico, el cual había adquirido un tono amarillo anaranjado, producía un

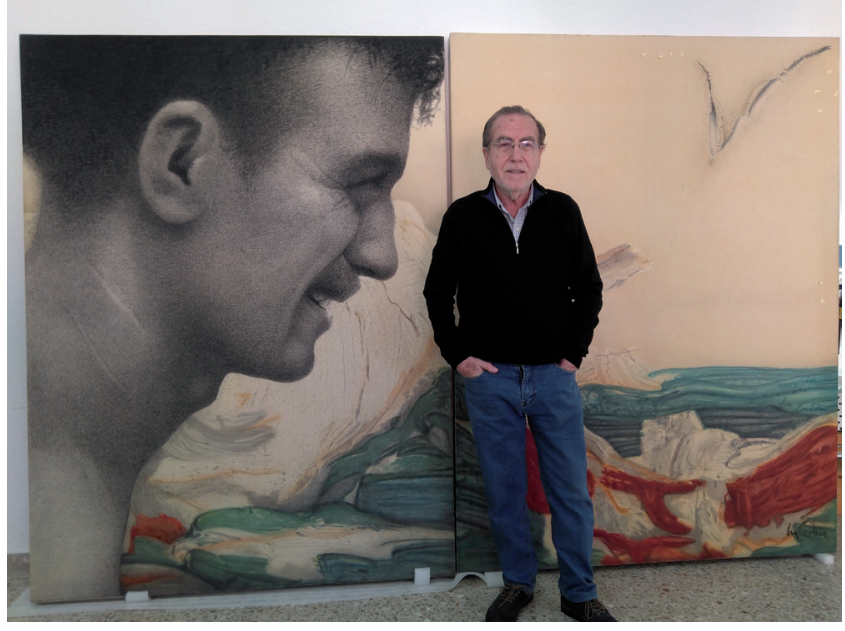

Figura 1.- Manuel Boix junto a la obra Pintar la Mar antes de la restauración, durante la entrevista realizada en las instalaciones del Servicio de Restauración de la Diputación de Castellón. Foto: Rosalía Torrent. impacto negativo sobre la obra en opinión del artista. De hecho podía apreciarse la acumulación de la resina sobre las fibrillas del algodón formando acumulaciones granulares ásperas. Así, al comparar ambos dípticos, se apreciaba una importante descompensación cromática al mostrar el lienzo derecho una mayor acumulación de resina, mucho más visible en los bordes de las crucetas de los bastidores, además de varias manchas de oxidación. Por contra, los laterales no barnizados, acumulaban suciedad, huellas dactilares y cercos en la parte superior [figuras 2 y 3 ].

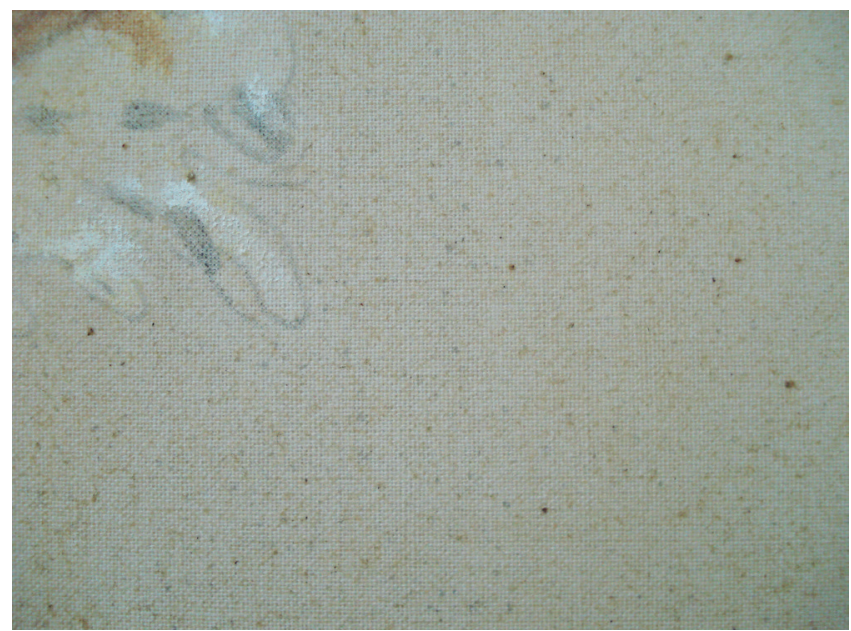

Figura 2.- Detalle del dibujo y acumulación del barniz amarilleado sobre el díptico derecho. Foto: Mayte Pastor.

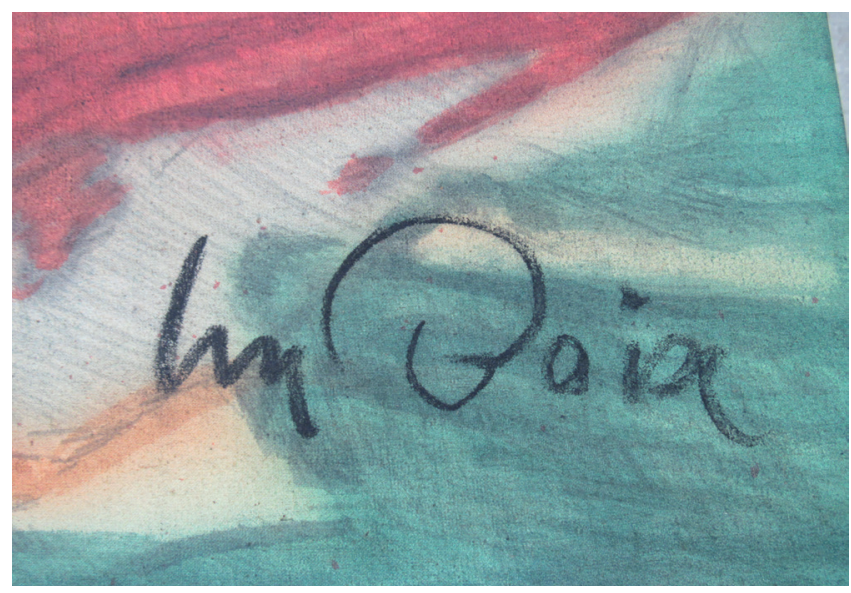

Figura 3.- Detalle de la firma a carboncillo y dibujo (lápiz, grafito, óleo diluido) sobre loneta de algodón en el díptico derecho. Foto: Mayte Pastor 
El Museo de Arte Contemporáneo Vicente Aguilera Cerni de Vilafamés (MACVAC) solicitó la restauración de obra al Servicio de Restauración de la Diputación de Castellón. Tanto la caracterización de los materiales como el estudio de la evaluación de los sistemas de limpieza fueron llevados a cabo con el apoyo del Institut Valencià de Conservació i Restauració $(I V C R+i)^{[2]}$.

Tras llevar a cabo un estudio estratigráfico, análisis FTIR y cromatografía, pudo determinarse que el óleo fue mezclado con barniz alquídico (resina de poliéster modificada con aceite de linaza) a fin de obtener distintos grados de transparencia, siendo este mismo tipo de resina la empleada en el acabado final. Las analíticas realizadas con SEM-EDX ratificaron la existencia de cargas de sílice como aditivo del barniz, las cuales suelen emplearse a fin de dar un acabado mate-satinado. Pese a que en un primer momento Boix mencionó el uso de laca de cabello Nelly ${ }^{\circledR}$ como fijativo del dibujo central, las analíticas no aportaron datos sobre la existencia de copolímeros acrílicos procedentes de este producto cosmético. El uso de pigmentos con contenido en plomo fue así mismo identificado mediante SEM-EDX en las pinceladas de color amarillo y anaranjado. Por contra, el microanálisis EDX puso de manifiesto la naturaleza prevalentemente orgánica del color verde ${ }^{[3] .}$

Según la empresa Industrias Titán, con la que se contactó a fin de solicitar muestras y recabar información sobre la composición de los barnices fabricados en los 80, aquellos barnices alquídicos formulados con aceite de linaza amarillean de forma inmediata. En base a la información aportada por el fabricante, este amarilleo responde a una oxidación por apertura de los dobles enlaces correspondientes a las insaturaciones de las cadenas de los ácidos grasos, por tanto, para su retirada son necesarios solventes que también sean capaces de disolver la pintura al óleo ${ }^{[4]}$.

Por lo que respecta al nivel óptimo de limpieza, Manuel Boix estableció como referencia la tonalidad del tejido de los laterales de los lienzos no barnizados ${ }^{[5]}$, aconsejando en un primer momento el lijado como sistema de limpieza para rebajar el barniz. El elevado riesgo que entrañaba dicha operación tanto por la posibilidad de alterar las zonas de color como por provocar manchas irreversibles y/o graves erosiones del tejido, motivó la realización de un estudio de evaluación de los riesgos y viabilidad de dicho tratamiento. Debido a su elevada complejidad, este se centró de forma exclusiva en la evaluación de la incidencia de la retirada del estrato alquídico final.

\section{Metodología}

La metodología empleada en el estudio se basó en la preparación y caracterización de probetas realizadas en base a los resultados del estudio material de la obra real junto a la información aportada por el artista en diversas entrevistas. Con motivo de evaluar el riesgo y efectividad de los sistemas de limpieza propuestos (medios abrasivos físico-mecánicos, solvent surfactant gels, geles siliconados de solventes, así como nanogeles químicos), fue necesario diseñar un protocolo fundamentado en el uso de distintas técnicas de análisis morfológico (videomicroscopio y SEM) y espectroscópico (EDX y FTIR-ATR), colorimetría y medición del brillo especular. Tanto las técnicas microscópicas como las espectroscópicas fueron necesarias para determinar los cambios morfológicos (erosión de la superficie), la eficacia de la retirada del barniz, así como la conservación del color y determinar la posible permanencia de residuos asociados a los sistemas de limpiezas aplicados (restos de gelificantes/ espesantes), confrontando los resultados obtenidos para determinar el impacto y seguridad de cada uno de ellos.

En la preparación de las probetas se utilizó una tela $100 \%$ algodón tensada en un bastidor, la cual fue aprestada con cola de conejo y posteriormente lijada. Se trazaron cuatro franjas horizontales sobre las que respectivamente fueron aplicados un barniz de base alquídica Titán ${ }^{\circledR}$, trazos de grafito y carboncillo, y pinturas al óleo rojo cadmio y verde esmeralda de la marca Titán ${ }^{\circledR}$ mezcladas con barniz alquídico y esencia de trementina, tratando de imitar las veladuras existentes en la obra real. Tras el secado, se aplicó mediante brocha una capa de barniz alquídico Titán ${ }^{\circledast}$ en toda la superficie. En este caso era de mayor interés generar una capa con un fuerte amarilleo similar al de la obra original que reproducir las condiciones de exposición solar anteriores a las actuales, controladas dentro del programa de conservación preventiva del museo. Según lo anterior, se decidió recurrir a un envejecimiento de los materiales aplicados en las probetas de tipo fotooxidativo por exposición a radiación solar ${ }^{[6]}$.

Finalmente, cada una de las franjas fue dividida en 11 tiras de $90 \times 30$ mm, formando cuatro series (A: barniz sin color, B: carboncillo y grafito, C: rojo y D: verde), [figura 4]. De las 10 probetas de cada serie, 5 se utilizaron para poner a punto el método de limpieza, mientras que las restantes se destinaron para la evaluación de los sistemas de limpieza finalmente seleccionados, reservando una de ellas como muestra patrón o control.

Cabe señalar que ante las limitaciones que planteaba reproducir el histórico de condiciones ambientales a las que se expuso la obra y la obtención actual de barnices fabricados en los años 80, fue necesario realizar una serie de pruebas preliminares a fin de acotar la selección de los sistemas de limpieza a evaluar. Para ello, de forma paralela al uso de probetas fue necesario recurrir a la obra real empleando pequeñas secciones aproximadas de $0^{\prime} 4 \mathrm{x}$ 0 '6 cm situadas en borde superior del díptico derecho. Se realizó el test de solventes (etanol, acetona e isooctano; dimetilsulfóxido-etilacetato), se espesaron las mezclas que daban mejores resultados con los sistemas Pemulen ${ }^{\text {TM }}$ TR-2 y Velvesil Plus ${ }^{\circledR}$, se probó la gama completa de 


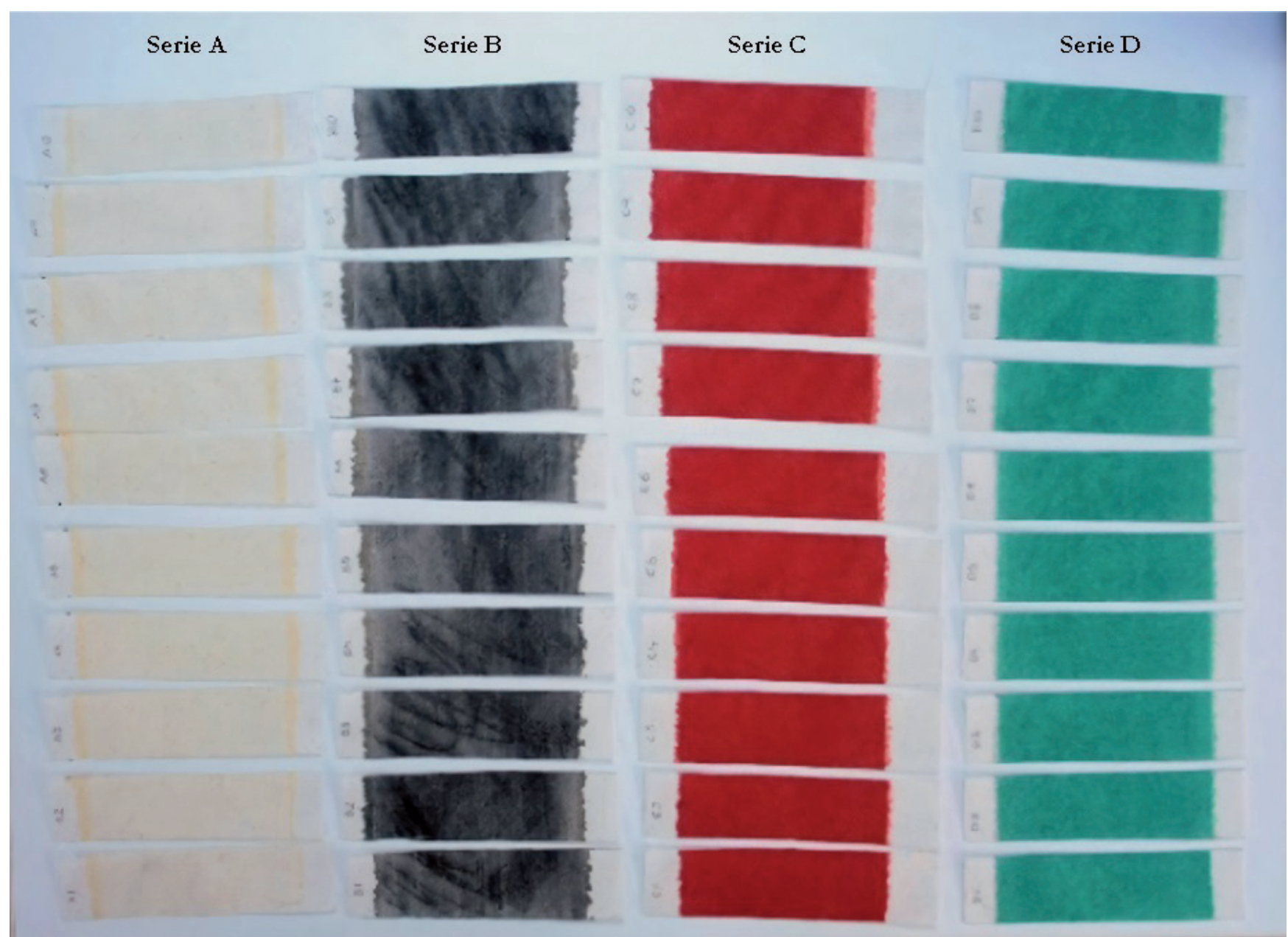

Figura 4.- Probetas de ensayo recortadas y numeradas. Foto: Maite Ciganda.

productos Nanorestore $\mathrm{Gel}^{\circledR}$ y Nanorestore Cleaning ${ }^{\circledR}$ y se incluyeron las propuestas de Boix. Teniendo en cuenta los resultados preliminares, la postura del artista, así como la necesidad de diseñar un sistema de limpieza capaz de actuar de forma homogénea sobre el barniz evitando la formación de cercos sobre la tela y la acumulación de residuos, fueron seleccionados finalmente los cuatro sistemas especificados a continuación.

- Lijas: Se testaron dos tipos, una lija de papel convencional gris de grano 1200 (serie de probetas A9-B9-C9-D9) y una malla perforada con partículas cerámicas abrasivas de Abranet $^{\circledR}$ ACE Mirka con granulometría 1000 (serie de probetas A8-B8-C8-D8). En ambos casos su aplicación consistió en ejercer una acción mecánica manual, aspirando posteriormente la superficie.

- Solvent Surfactant Gels (en adelante SSG): Debido a la capacidad solvente de la mezcla dimetilsulfóxido (en adelante DMSO) y Etil Acetato (10:90) frente al barniz alquídico, según los resultados del test previo, fue gelificada empleando Ethomeen $\mathrm{C}-12^{\circledR}$ y Pemulen ${ }^{\mathrm{TM}}$ TR-2 (Cremonesi et al., 2012; Cremonesi, 2016). El gel fue aplicado a pincel sobre papel rayón Usukuchi de 12 gramos, siendo cubierto durante 120 minutos con un film plástico para evitar el secado del gel. El papel rayón Usukuchi a base de celulosa modificada, suave, flexible y con baja opacidad, permitía el control de la limpieza y una fácil retirada. Posteriormente, se realizó una primera remoción del gel en seco a través de la retirada del papel de celulosa y utilización de hisopos de algodón, seguida de ulteriores aclarados con la mezcla DMSO y Etil Acetato (10:90). El sistema se probó en la serie de probetas A7B7-C7-D7.

- Nanogeles: Se empleó el hidrogel Nanorestore Gel ${ }^{\circledR}$ Dry (gel pHEMA/PVP), el cual, según las instrucciones del fabricante (CSGI, 2015), fue previamente cargado durante 12 horas en la solución Nanorestore Cleaning ${ }^{\circledR}$ Polar Coating $S$ aditivada con Etil Acetato ${ }^{[7]}$. Este tipo de nanoemulsión, la cual había aportado una mayor capacidad de retirada del barniz en las catas ejecutadas en la obra, combina la acción de tensoactivos y solventes. Una pequeña porción de nanogel cargado fue dispuesta sobre las probetas A5-B5-C5-D5, colocando sobre éste un film de poliéster monosiliconado y peso para aumentar el contacto entre la superficie y el gel. Tras 120 minutos, se retiró el gel y se eliminaron los posibles restos de tensoactivo con un hisopo de algodón humedecidos con agua desionizada. 
-Disoluciones espesadas en geles siliconados (en adelante Velvesil Plus ${ }^{\circledR}$ ): Tras impregnar la superficie de la probeta con Ciclometicona pentamera D5 a modo de pantalla para evitar la penetración en la tela de la mezcla de DMSO y Etil Acetato (10:90) espesada con Velvesil Plus ${ }^{\circledR}$, fue aplicada sobre papel rayón dejándola actuar durante 20 minutos. Concretamente se emplearon $2 \mathrm{ml}$ de la mezcla solvente por 8 gramos de Velvesil Plus ${ }^{\circledR}$ y unas gotas de D5 hasta obtener una consistencia adecuada. Posteriormente, se retiró el papel, se extrajeron los restos de gel mediante un hisopo en seco y se realizaron sendos aclarados, uno con DMSO-Etil Acetato y otro con D5.

Las probetas utilizadas fueron las A6-B6-C6-D6. Aclarar que el sistema Pemulen ${ }^{\text {TM }}$ TR-2 y Velvesil Plus ${ }^{\circledR}$ fueron comparados como espesantes de la misma mezcla solvente, empleando a su vez la misma metodología de aplicación con motivo de estudiar el riesgo de permanencia de residuos.

Tal y como señalamos anteriormente, en cada una de las probetas se llevó a cabo un estudio morfológico y análisis composicional previo y posterior a la aplicación de los sistemas de limpieza especificados. Las imágenes de superficie fueron tomadas con 30x y 80x aumentos empleando un video-microscopio digital Dino Lite ${ }^{\circledR}$ Premier. Para la caracterización del color y el cálculo de la diferencia total de color $\Delta \mathrm{E}^{*}$ se utilizó un espectrofotómetro portátil CM-700d KONICA MINOLTA con fuente de iluminación difusa (lámpara de xenón pulsada) y un ángulo de visión de $8^{\circ}$. La diferencia total de color $\Delta \mathrm{E}^{*}$ definida como la distancia geométrica entre sus posiciones en el espacio de color CIE 1976 fue calculada mediante la fórmula: $\Delta \mathrm{E}^{*}=\left[\Delta \mathrm{L}^{*} 2+\Delta \mathrm{a}^{*} 2+\Delta \mathrm{b}^{*} 2\right] 1 \frac{1}{2}$ (AENOR, 1994; Ortiz et al., 2010). Así mismo se utilizó un brillómetro Statistical Glossmeter 407 ELCOMETER ${ }^{\circledR}$ realizando mediciones a $60^{\circ}$ sobre un área de $10 \times 70 \mathrm{~mm}$ aproximadamente (AENOR, 1999).

Las micrografías de microscopía electrónica de barrido (SEM) y los microanálisis elementales por energía dispersiva de rayos $X(E D X)$ se obtuvieron con un microscopio Hitachi Ltd. S-3400N (VP-SEM), equipado con un espectrómetro de rayos $\mathrm{X}$ de energía dispersiva (EDX) Bruker Corporation XFlash $^{\circledR}$ con voltaje de aceleración de $20 \mathrm{kV}$ (Villegas Sánchez, 2002). Las probetas se observaron a diferentes aumentos en la modalidad de electrones retrodispersados (BSE).

A fin de determinar la existencia de residuos se hicieron análisis moleculares tanto de sustancias orgánicas e inorgánicas a través de un espectrómetro de infrarrojos por transformada de Fourier (FTIR) Bruker-Tensor II, dispositivo ATR de cristal de diamante y microscopio Bruker-Hyperion acoplado (Gutierrez, 1997; Skoog et al., 2008). Cabe señalar que previamente se analizaron los productos de limpieza testados para obtener espectros que sirvieran de referencia a la hora de detectar su presencia residual sobre las superficies tratadas.

\section{Resultados y discusión}

\section{—Variaciones de las propiedades físicas: color y brillo}

La lectura comparada de los valores promedio de $\Delta \mathrm{E}^{*}$ obtenidos para cada uno de los grupos de probetas y sistemas de limpieza ensayados, aportaron una valiosa información de la efectividad e impacto de cada uno de ellos. Dado el carácter sustractivo del procedimiento de limpieza, la variación total del color podría reflejar tanto la eliminación del barniz alquídico como la posible alteración de los estratos subyacentes de color o indicar a la permanencia de residuos. Los valores numéricos obtenidos para cada coordenada de color $\left(L^{*}, a^{*}, b^{*}\right.$ según la norma CIELAB 1976)8 antes y después de los ensayos de limpieza, se compararon obteniendo variaciones relacionadas con cada sistema ensayado. Dichas variaciones se interpretaron junto al examen visual y fueron complementadas con la información arrojada por otros sistemas de análisis empleados en este estudio.

La producción industrial de objetos coloreados aplica un valor admitido de diferencia de color entre dos objetos para evitar variaciones cromáticas cuando producen muchas unidades. Los valores de $\Delta \mathrm{E}^{*}$ considerados admisibles resultan ser muy bajos ya que entre 2 - 3,5 los cambios son percibidos por el ojo humano como colores distintos. La aplicación de un valor admitido presenta limitaciones en el ámbito patrimonial respecto a los tratamientos de limpieza, donde el estrato a retirar podría presentar una coloración elevada, como es el caso que nos ocupa (Ortiz et al., 2013; Antuñez et al., 2012). Puesto que la retirada de un material envejecido conlleva a priori la obtención de valores altos de $\Delta \mathrm{E}^{*}$, el establecimiento de una cifra como rango de seguridad se convirtió en una decisión compleja. Al respecto señalar, que se optó por un valor menor o igual a 2, siempre con matices y teniendo en cuenta los resultados de otras pruebas (ej. observaciones al SEM: disminución del estrato del barniz, cambios morfológicos y presencia de residuos).

Como se muestra en la gráfica de la Figura 5, las probetas de la Serie A, con estrato de barniz alquídico, presentaban las mayores variaciones de color tras el testado del sistema SSG, con un $\Delta \mathrm{E}^{*}=7,73$ destacando el aumento del valor $b^{*}$ (viraje hacia el amarillo) interpretando la causa a la permanencia de residuos. Sin embargo las muestras tratadas con Velvesil Plus $^{\circledR}$, nanogel y lijas aportaron pocos cambios, registrando un $\Delta \mathrm{E}^{*}$ inferior a 2, el cual fue interpretado como una variación cromática imperceptible para el ojo humano y por tanto admisible según el límite establecido. En todos los casos, la retirada del estrato de barniz fue efectiva.

En la Serie B (grafito y carboncillo), los sistemas de solventes en Velvesil Plus ${ }^{\circledR}$ y SSG mostraron variaciones cromáticas con un $\Delta E^{*}=1,55$ y 1,75 respectivamente, siendo interpretados estos valores como la sola retirada del barniz. El mayor nivel de variación de color fue obtenido tras la aplicación 
del nanogel, registrando un $\Delta \mathrm{E}^{*}=4,16$ predominando la disminución de $L^{*}$ (menor luminosidad), y siendo interpretado este resultado como una mayor disolución y retirada de la capa de barniz y de color.

La limpieza mecánica por lijado aportó los mayores cambios en las muestras de la Serie C (óleo rojo cadmio), siendo la variación más pronunciada aquella aportada por la lija convencional con un $\Delta \mathrm{E}^{*}=13,04$, destacando la disminución del valor $b^{*}$ (viraje hacia el azul). Fueron los solventes gelificados en Velvesil Plus ${ }^{\circledR}$ los que produjeron los menores cambios con un $\Delta E^{*}=1,12$.
Las probetas pertenecientes a la Serie D (óleo verde esmeralda), registraron un mayor nivel de cambios tras utilizar la lija convencional alcanzando un $\Delta E^{*}=10,25$ acentuándose el aumento del valor en la coordenada $a^{*}$ (viraje hacia el rojo). La menor variación fue registrada con el uso de los nanogeles $\left(\Delta \mathrm{E}^{*}=1,61\right)$.

En general, las variaciones del brillo especular fueron bajas en todas las probetas [tabla 1], siendo detectada una tendencia a su disminución que se interpretó, teniendo en cuenta conjuntamente los valores de $\Delta \mathrm{E}^{*}$, con la retirada del barniz alquídico.

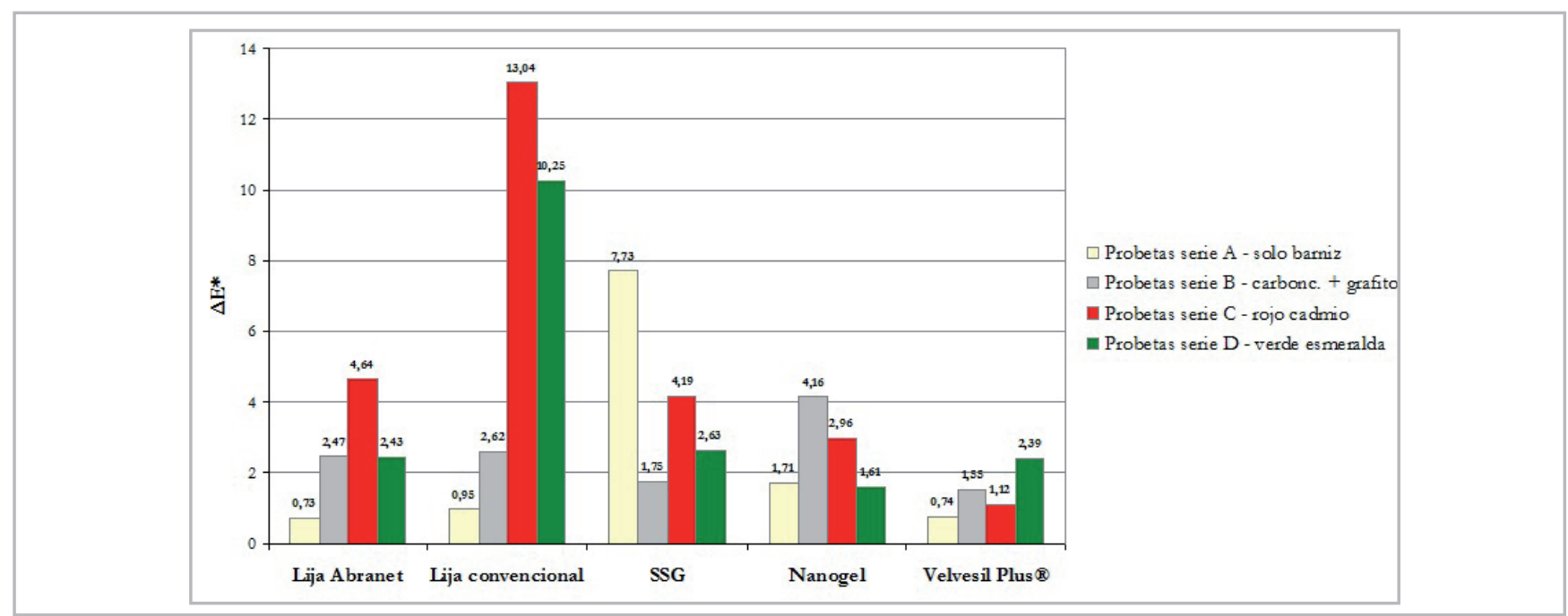

Figura 5.- Comparación de los valores $\Delta \mathrm{E}^{*}$ de las series de probetas en base al sistema de limpieza. Gráfico: Livio Ferrazza.

Tabla 1.- Comparación de los valores $\Delta \mathrm{E}^{*}$ de las series de probetas en base al sistema de limpieza. Gráfico: Livio Ferrazza.

\begin{tabular}{|c|c|c|c|c|c|c|c|c|c|c|c|c|c|c|c|c|c|c|c|c|}
\hline \multicolumn{21}{|c|}{ VARIACIONES DEL BRILLO ESPECULAR } \\
\hline $\begin{array}{l}\text { SISTEMA DE } \\
\text { LIMPIEZA }\end{array}$ & \multicolumn{4}{|c|}{$\begin{array}{c}\text { LIJA } \\
\text { CONVENCIONAL }\end{array}$} & \multicolumn{4}{|c|}{ LIJA ABRANET ${ }^{\circledast}$} & \multicolumn{4}{|c|}{$\begin{array}{c}\text { SOLVENT } \\
\text { SURFACTANT } \\
\text { GEL }\end{array}$} & \multicolumn{4}{|c|}{ NANOGEL } & \multicolumn{4}{|c|}{$\begin{array}{c}\text { VELVESIL } \\
\text { PLUS }^{\circledR}\end{array}$} \\
\hline PROBETAS & A9 & B9 & C9 & D9 & A8 & B8 & $\mathrm{C} 8$ & D8 & A7 & B7 & $\mathrm{C} 7$ & D7 & A5 & B5 & $\mathrm{C} 5$ & D5 & A6 & B6 & C6 & D6 \\
\hline $\begin{array}{l}\text { Medición } \\
\text { inicial }\end{array}$ & 3,2 & 1,0 & 1,5 & 1,7 & 3,2 & 1,0 & 1,7 & 1,5 & 3,2 & 1,1 & 1,6 & 1,5 & 3,2 & 1,0 & 1,5 & 1,5 & 3,2 & 1,0 & 1,6 & 1,5 \\
\hline $\begin{array}{l}\text { Medición } \\
\text { final }\end{array}$ & 2,9 & 1,1 & 1,5 & 1,5 & 3,0 & 1,2 & 1,7 & 1,6 & 2,9 & 1,1 & 1,5 & 1,4 & 3,0 & 1,0 & 1,4 & 1,5 & 3,0 & 1,0 & 1,4 & 1,4 \\
\hline
\end{tabular}

\section{—Cambios morfológicos}

Tal y como se expresa al inicio de este texto, los sistemas de limpieza debían retirar el estrato de barniz alquídico sin provocar cambios en los estratos subyacentes a conservar (tejido y dibujo en sus distintas técnicas). A excepción de la limpieza mecánica por lijado, la actuación físico-química del resto de sistemas implicaba la disolución de la resina y una acción mecánica. En estos casos, los posibles cambios estructurales en los estratos podían ser evaluados a nivel microscópico aportando una valiosa información en la toma de decisiones.
A) Lijas: Las imágenes obtenidas con SEM reflejaron la fuerte erosión y alisado de los puntos convexos de los hilos del tejido de las probetas, donde además se pudieron identificar las líneas de dirección de la acción mecánicaabrasiva. Esta erosión se pudo observar tanto para la limpieza con lija convencional [figura 6a-b], como para la lija Abranet $^{\circledast}$ [figura 6c-d]. Asimismo, pudieron apreciarse la inclusión de partículas en los intersticios de las fibras, y posibles restos de fibras de algodón.

B) SSG: Mediante las imágenes tomadas con SEM pudo comprobarse la eliminación de la capa de barniz, dejando las fibras de los hilos a vista, mientras que parte del sistema 
gelificado quedaba acumulado en las oquedades del entramado. Además, quedó patente el desgaste sufrido en las fibras debido a la acción mecánica del aclarado [figura 7].

C) Nanogeles: Las observaciones reflejaron una retirada generalmente homogénea de la capa superficial de barniz quedando las fibras en superficie libres de resina, lo cual podía apreciarse claramente en la probeta A5 [figura 8a]. Se observó que en general, este sistema de limpieza no afectaba a la morfología de las fibras por rotura o fragmentación.

D) Velvesil Plus ${ }^{\oplus:}$ Las imágenes SEM advirtieron un aplanado de la superficie irregular propia del entramado de la tela, unido a un pronunciado desgaste con puntos de rotura de las fibras de algodón, a causa de la acción mecánica durante el aclarado necesaria para retirar el barniz [figura 8b].
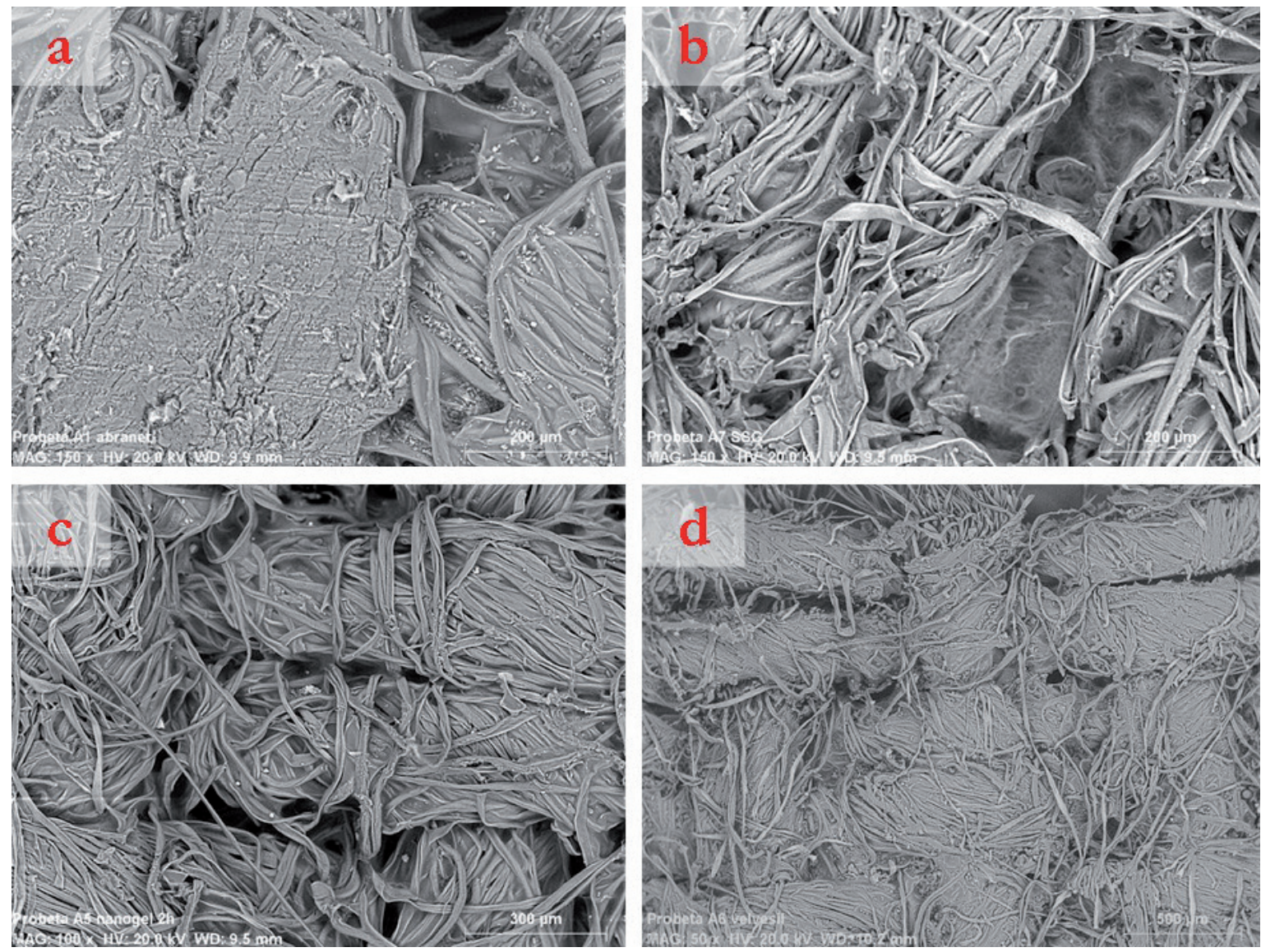

Figura 6.- Detalles de las superficies de las probetas después del tratamiento de limpieza con lija convencional y Abranet ${ }^{\oplus}$. Imágenes SEM, a diferentes aumentos, en modalidad electrones retrodispersados BSE. Foto: Livio Ferrazza.
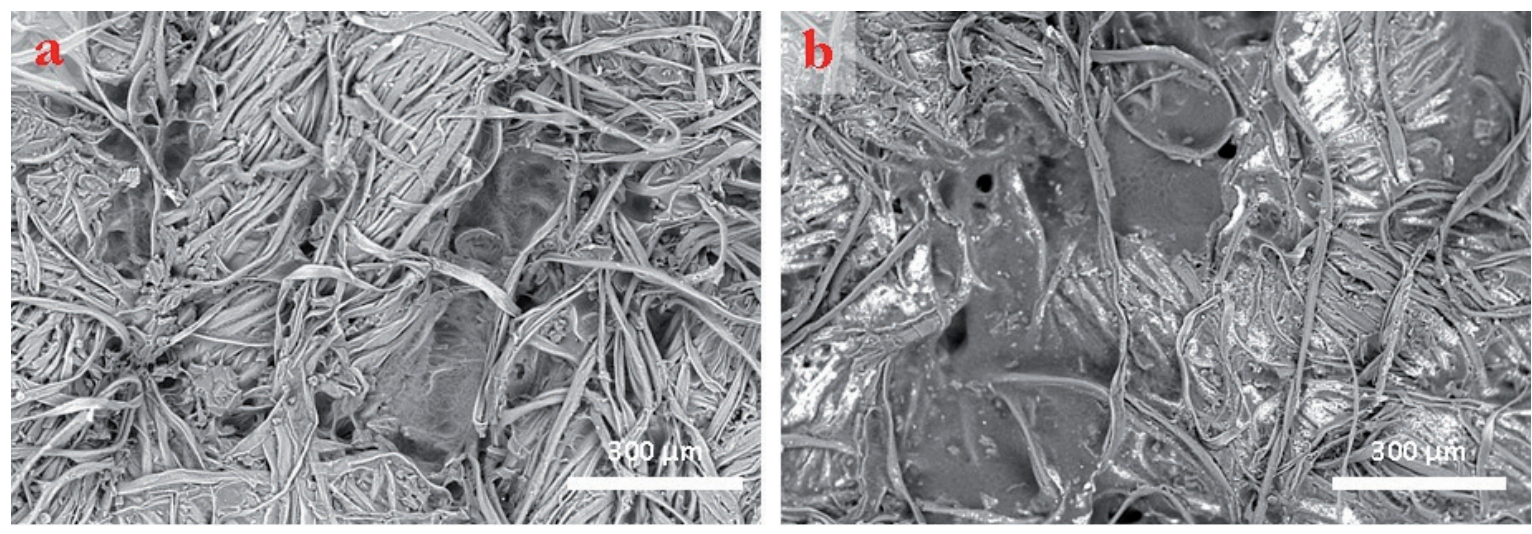

Figura 7.- Detalles de las superficies de las probetas A7 (a) y D7 (b) después del tratamiento de limpieza con SSG. Imágenes SEM en modalidad electrones retrodispersados BSE. Foto: Livio Ferrazza. 

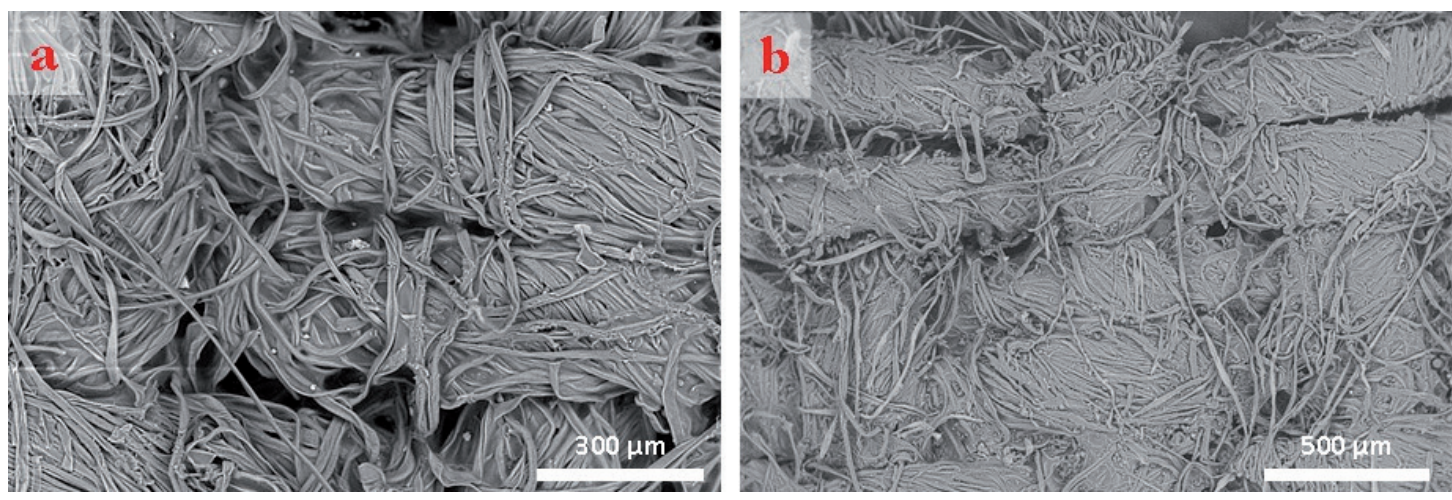

Figura 8.- Detalles de las superficies de las probetas después del tratamiento de limpieza. Imágenes SEM en modalidad electrones retrodispersados BSE. Foto: Livio Ferrazza.

\section{-Presencia de residuos}

A) Lijas: Los estudios microscópicos y espectroscópicos realizados mediante SEM-EDX y FTIR-ATR antes y después de la limpieza no reflejaron variaciones compositivas evidentes en las probetas. Este resultado indicaría la total ausencia de residuos relacionados con el sistema de limpieza aplicado.

B) SSG: Las observaciones mediante SEM distinguieron una acumulación de materia orgánica, morfológicamente similar al gel aplicado, en las oquedades del entramado del soporte textil [figura 9], la cual fue corroborada mediante FTIR-ATR [figura 10]. En este sentido, en el espectro de la probeta D7 (verde esmeralda), se identificaron bandas marcadores característicos del SSG con el doblete a 2923 $\mathrm{cm}^{-1}$ y $2653 \mathrm{~cm}^{-1}$ y la banda de absorción a $1567 \mathrm{~cm}^{-1}$.

C) Nanogeles: Tras la interpretación de los espectros composicionales, no pudieron detectarse restos de componentes procedentes de este sistema de limpieza. El análisis FTIR-ATR, tanto del hidrogel por separado como de las probetas antes y después de los ensayos, no reflejaron la presencia de residuos.

D) Velvesil Plus ${ }^{\oplus}$ : A partir del exámen microscópico mediante SEM pudieron individualizarse partículas adheridas a las fibras y acumuladas en los intersticios del entramado textil [figura 9a]. En este sentido, el mapa obtenido a través de EDX reflejaron la presencia de silicio [figura 9b], identificando mediante FTIR-ATR una banda de absorción a 799 cm-1 que difería y destacaba del espectro patrón de la probeta de la serie B [figura 11]. Atendiendo al patrón de referencia del Velvesil Plus ${ }^{\circledR}$ esta banda fue considerada un marcador de la presencia del producto aplicado. Concretamente, los residuos resultaban ser más abundantes en las probetas de color que en aquellas simplemente barnizadas. Este hecho pudo explicarse atendiendo a la mayor sensibilidad del estrato de color a ser removido durante el proceso de aclarado, donde fue ejercida una acción mecánica con el hisopo. Dado que durante este proceso los hisopos causaban la parcial remoción del estrato pigmentado, el aclarado debía ser necesariamente poco insistente, dejando en superficie parte de los residuos de Velvesil Plus ${ }^{\oplus}$.

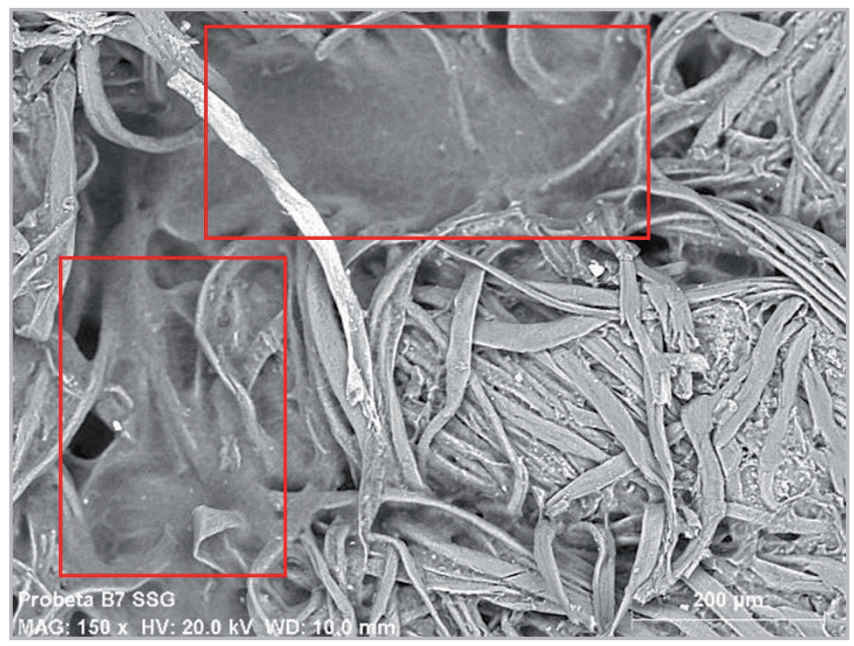

Figura 9.- Imagen SEM en modalidad electrones retrodispersados BSE de un área de la probeta de la serie B después del tratamiento con SSG. Se marcan las áreas donde hay una acumulación de materia orgánica correspondiente al producto aplicado. Foto: Livio Ferrazza.

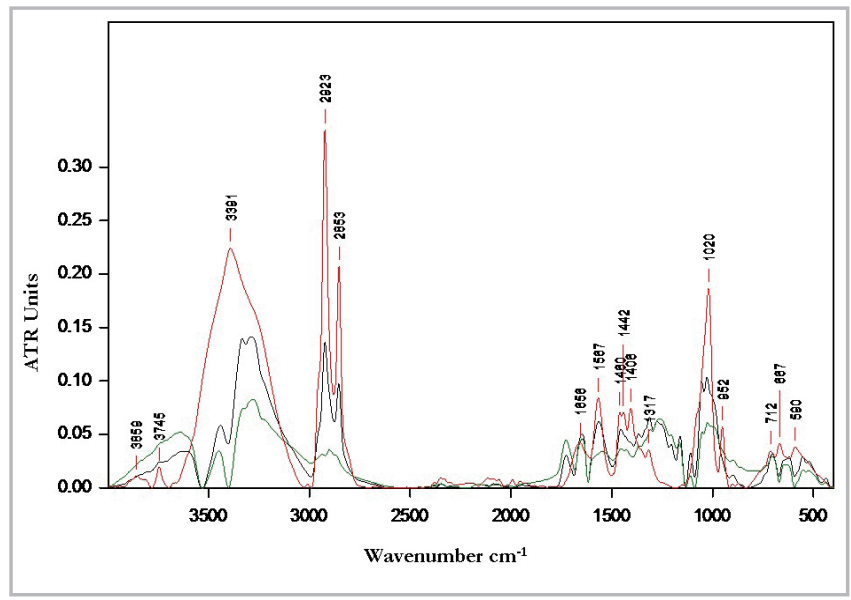

Figura 10.- Espectro FTIR patrón del SSG (rojo). Espectro de la probeta sin tratamiento (verde) y después del tratamiento (negro). Fuente: Livio Ferrazza. 

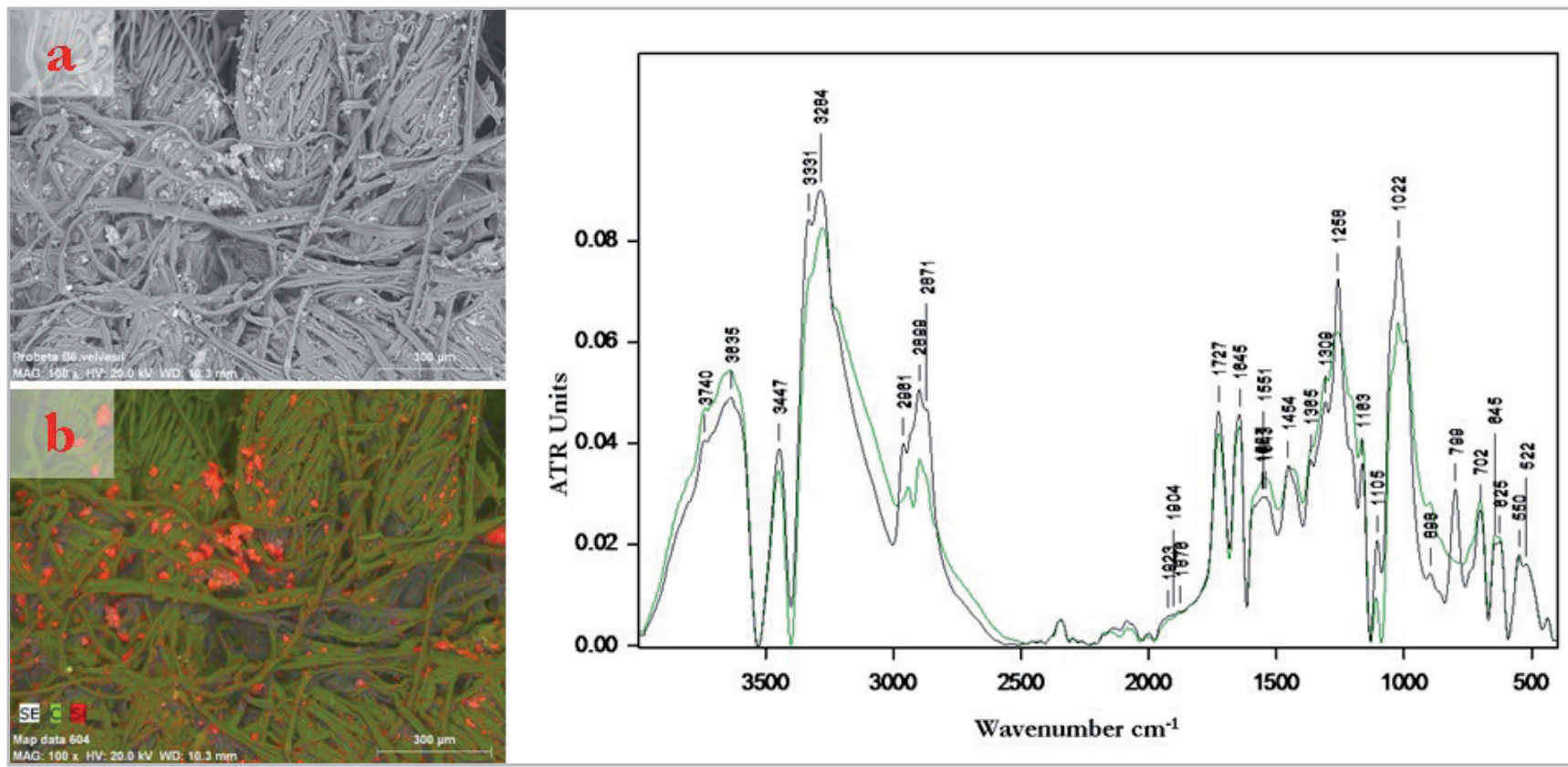

Figura 11.- a) Imagen SEM en modalidad electrones retrodispersados BSE de un área de la probetas después del tratamiento con Velvesil Plus ${ }^{\oplus}$. b) Mapa de distribución que evidencia los residuos a base de silicio. A la derecha espectro FTIR de la probeta sin tratamiento (verde) y después (negro) donde se evidencia el pico a $799 \mathrm{~cm}^{-1}$. Foto: Livio Ferrazza.

\section{Aplicación del protocolo de evaluación a la restauración de Pintar la mar:}

La retirada del barniz alquídico fue sin duda el proceso más complejo de la restauración de esta obra9. A partir de los resultados del protocolo de evaluación de los sistemas de limpieza, fue necesario efectuar diversos ajustes debido a las diferencias entre las probetas (barniz: composición, distribución irregular con acumulaciones, textura áspera y nivel de envejecimiento) y el lienzo (tejido sin desmontar del bastidor). Dentro de estos ajustes destacan la necesidad de incremento del tiempo de actuación de la disolución espesada y repetición del proceso de limpieza y/o aclarado respecto al empleado en las probetas, así como la detección de una mayor sensibilidad de la tela original al aclarado con agua para los hidrogeles. Paralelamente, fue el autor quien estableció en todo momento el nivel adecuado y dió el visto bueno a los sistemas aplicados, aportando soluciones en las distintas fases.

Los mejores resultados para la limpieza del fondo de la obra fueron obtenidos empleando la disolución espesada en Velvesil Plus ${ }^{\circledR}$, testada en el protocolo anteriormente descrito. En primer lugar, se aplicó una capa generosa de ciclometicona D5a pincela modo de pantalla para minimizar su penetración y acumulación en el tejido y en segundo lugar, sobre papel rayón, una capa del mencionado gel a pincel. Tras unos 15-20 minutos de exposición, se retiró el papel y los residuos en seco mediante hisopos de algodón. Finalmente, se llevó a cabo un minucioso aclarado con la mezcla solvente y dos pasadas de Ciclometicona D5 [figura 12]. En zonas puntuales donde el barniz era muy espeso (líneas de acumulación sobre crucetas) o en las que había manchas de oxidación muy oscuras (díptico derecho), fue necesario emplear un gel de alcohol bencílico y xileno (1:1) según el sistema de gelificado y aclarado descrito en la metodología. Igualar el nivel de limpieza fue también un proceso muy complicado, de ahí que la disolución espesada tuviera que aplicarse de 2 a 4 veces según zonas, igualando acumulaciones, líneas de limpieza y sombras. No siempre pudo conseguirse una total homogeneidad tonal, aunque sí un adelgazamiento visible del estrato.

Las pruebas realizadas con el sistema de nanogeles (Nanorestore Gel ${ }^{\circledR}$ Dry y Cleaning ${ }^{\circledR}$ Polar S: de 30 minutos a 2 horas de exposición) fueron muy positivas en las zonas pintadas al óleo, puesto que el sistema anterior comprometía la solubilidad de los colores y era susceptible de dejar residuos al no poder realizar una limpieza físicoquímica y mecánica intensiva. Por contra, en las áreas

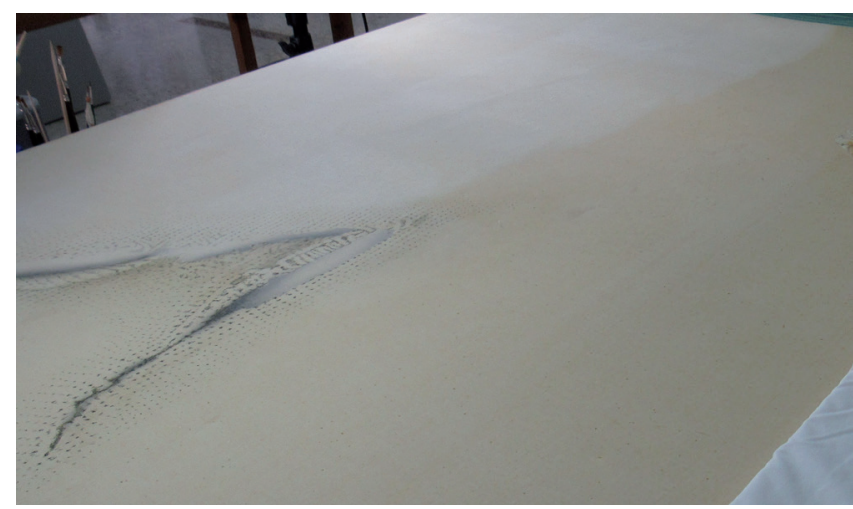

Figura 12.- Detalle del proceso de limpieza del díptico derecho. Ver diferencia entre la parte superior (en proceso de adelgazamiento del barniz) y la inferior de la imagen (con barniz). Foto: Mayte Pastor. 
barnizadas sobre la tela con ausencia de color, el aclarado con agua y esponja recomendado para retirar los restos de surfactante era contraproducente, provocando el hinchado y una notable modificación superficial de las fibras de algodón del soporte textil. Recordemos que a diferencia de las probetas, el barniz fue aplicado a compresor con una disposición irregular de resina.

Tras retirar lo máximo posible el barniz, pudo comprobarse la existencia de otra capa anaranjada, heterogénea y grumosa, la cual correspondía a la cola de conejo aplicada por el autor para preparar el soporte. Su retirada no se incluyó en el protocolo de evaluación al ser un estrato finalmente conservado a causa de su función tensora y de apresto de la tela.

Señalar que finalmente, solo se eliminó el barniz del fondo en ambos dípticos, no así de las partes con pintura o dibujo a excepción de la gaviota. Esto es, se realizó una limpieza selectiva muy compleja, sin desmontar el bastidor, en horizontal y durante más de 5 meses. Esta procuró adelgazar todo lo posible el nivel de barniz, siendo mucho más intensa en el díptico derecho que en el izquierdo debido a su mayor presencia y disposición (acumulación en las líneas de las crucetas, alrededor del dibujo de la gaviota, etc.). Mediante la misma, se consiguió rebajar el impacto negativo que a juicio del autor aportaba el estrato de protección envejecido, no siendo necesario finalmente efectuar la misma operación sobre la parte pintada (95\% del díptico derecho y parte inferior del izquierdo) al quedar estéticamente integrada ${ }^{[10]}$.

\section{Conclusiones}

La restauración de la obra Pintar la mar de Manuel Boix, ha puesto de manifiesto una vez más la necesidad de realizar estudios previos de evaluación capaces de analizar la viabilidad de los tratamientos. En este caso, el diseño de un protocolo de limpieza a través de un sistema de testado con pruebas "in vitro" e"in vivo" fue decisivo en la valoración de la incidencia de cada tipo de medio y producto, en función de las distintas zonas de la obra. Estas pruebas son importantes a la hora de determinar la eficacia y el riesgo de un tratamiento en sí mismo irreversible, pues con la retirada de un estrato de suciedad y/o barniz pueden venir asociadas diversas variaciones morfológicas y ópticas superficiales, junto a la permanencia de residuos derivados principalmente del sistema espesante.

Sin los datos obtenidos a partir de las pruebas anteriores, hubiera sido difícil establecer una metodología de intervención rigurosa, efectiva y con las suficientes garantías para respetar la integridad de la obra más allá de lo meramente visual. Una integridad que debe entenderse en cuanto a lo matérico y conceptual, pues en el caso descrito anteriormente, la opinión del artista fue decisiva en el establecimiento del impacto de las alteraciones del barniz y en los objetivos a alcanzar con la limpieza.
Según lo anterior, el uso de probetas de ensayo en el diseño de este tipo de tratamientos en obra contemporánea resulta una herramienta muy útil, dada la falta de publicaciones con casos similares, a causa de la heterogeneidad de materiales que el conservador-restaurador puede encontrar y a la dificultad de conseguir productos de la época para testar. Por tanto, esta metodología, que como se ha señalado, presenta evidentes limitaciones en cuanto al grado de similitud de las probetas respecto a la obra real, responde a la necesidad de ensayar y evaluar determinados tratamientos sin poner la obra en riesgo, reduciendo a su vez el número de test a realizar. Dichas limitaciones obligan a realizar ajustes, no obstante las ventajas son considerables.

Respecto a la elección del sistema de limpieza más adecuado para este caso, a partir de la correlación de los resultados obtenidos y la valoración de la efectividad e impacto de cada sistema y material propuesto, se consideró como más factible para el tratamiento del fondo (tela barnizada sin color), la mezcla de solventes espesados en el gel siliconado Velvesil Plus ${ }^{\circledR}$. En cuanto a las zonas con color, el Nanorestore Gel ${ }^{\circledR}$ Dry cargado en la solución Nanorestore Cleaning ${ }^{\circledR}$ Polar Coating S, fue la más idónea. Sin embargo, ambos sistemas presentaban aspectos negativos como la permanencia de residuos de Velvesil Plus ${ }^{\circledR}$ en zonas delicadas donde no podía realizarse un aclarado en profundidad sin dañar el color, o por parte del nanogel y solución de limpieza de la CSGI, su elevado coste, tiempo de trabajo lento y sensibilidad de materiales como el algodón al posterior aclarado recomendado con agua. Un aclarado que necesitaba ser más intenso en la obra real que en las probetas.

Por otra parte, se plantea como línea de investigación abierta el estudio del envejecimiento de los posibles residuos de geles siliconados que pudieran quedar en los intersticios de las superficies tratadas, así como esencialmente respecto a su interferencia óptica y química a largo plazo. Sin duda, la permanencia de residuos en cuanto a los casos señalados del SSG y del Velvesil Plus ${ }^{\circledR}$ y concretamente en la tipología de superficies pictóricas estudiadas, viene a limitar o excluir su utilización a causa de la necesidad de efectuar un correcto proceso de aclarado, lo cual como se ha señalado a lo largo del texto, no era viable en superficies con ciertas texturas y colores sensibles.

\section{Agradecimientos}

A Manuel Boix, por su ayuda e inestimable apoyo durante la restauración de la obra. A Gemma Contreras Zamorano, subdirectora del IVCR+i, por su respaldo sin el cual no hubiera podido realizarse esta investigación. A Ruth Sanz, Diputada de Cultura de la Diputación de Castellón y a Núria Felip, Directora del Servicio de Restauración de la Diputación de Castellón por su confianza y soporte. A Rosalía Torrent, Directora del MACVAC y a Joan Feliu, 
Gestor del MACVAC, por su apoyo y ayuda. A Industrias Titán S.A.U. e Industrias Belloch, S.L., por su atención y colaboración.

\section{Notas}

[1] Fuente: entrevista telefónica a Manuel Boix (20/03/18) y entrevista en las instalaciones del Servicio de Restauración de la Diputación de Castellón el 09/04/17 y 09/04/18. Consultas por email realizadas en 2015, y durante 2018 al 2019. Entrevistas llevadas a cabo por Mayte Pastor Valls.

[2] Caracterización de materiales: Livio Ferrazza, IVCR+i. Técnico en conservación restauración: Mayte Pastor Valls, Servicio de Restauración de la Diputación de Castellón. Realización de probetas y testado de materiales: Maite Ciganda Azcarate, Proyecto final de Máster en Diagnóstico del estado de conservación del Patrimonio Histórico. Evaluación de sistemas de limpieza en obra contemporánea. Pintar la Mar, Manuel Boix (1986). Universidad Pablo de Olavide curso 2017-18.

[3] La laca Nelly ${ }^{\circledast}$ contiene un copolímero acrílico soluble en agua. Fuente: consulta telefónica con el laboratorio de Industrias Belloch, S.L. (Consulta realizada por Mayte Pastor Valls el 23/11/2005). La determinación de los componentes orgánicos se realizó con un espectrómetro de infrarrojos mediante transformada de Fourier (FTIR) Bruker-Tensor 27, utilizando un dispositivo de ATR y por cromatografía de gases - espectrometría de masas, utilizando un GC-MS QP5050A Shimadzu. Los análisis por dispersión de energías de rayos $\mathrm{X}$, se realizaron en un Bruker - Quantax X Flash, acoplado a un microscopio electrónico de barrido Hitachi S - 3400N. Informe AC31, realizado por Livio Ferrazza, IVCR+i.

[4] Debido al amarilleo de las resinas alquídicas con aceite de linaza estas se reservan a productos específicos destinados al tratamiento de suelos de madera rústicos o barcas pesqueras. Debido a protocolos internos de almacenaje, los productos con base disolvente no pueden almacenarse más allá de 5 años por lo que la empresa no pudo facilitar ninguna muestra para su testado. Fuente: A. Ortega, Responsable de Prescripción y Postventa Industrias Titán S.A.U. Email: 02/05/2018. Consulta realizada por Mayte Pastor Valls.

[5] Op. cit. Fuente: entrevistas realizadas a Manuel Boix.

[6] A fin de formar un estrato de barniz con un nivel de amarilleo lo más parecido al de la obra, las muestras se expusieron a la radiación solar durante $186 \mathrm{~h}$ que es el tiempo indicado en la norma ASTM D1183-03 para un ciclo de envejecimiento. Las muestras se colocaron al exterior en un ángulo de $45^{\circ}$ sobre un soporte rígido, inmovilizadas por una cinta adhesiva, registrando las condiciones climáticas con un termohigrómetro digital en base a la norma UNE 2810. Tras su exposición se almacenaron en la oscuridad a $18^{\circ} \mathrm{C}-28^{\circ} \mathrm{C}$ y una humedad relativa del $50 \pm 5 \%$.

[7] Nanorestore Cleaning ${ }^{\circledR}$ Polar Coating S: Fluido nanoestructurado a base de agua con un tensioactivo aniónico y una mezcla de 1-pentanol, acetato de etilo y carbonato de propileno. Diseñado para la eliminación de recubrimientos poliméricos (sintéticos acrílicos y vinílicos, barnices naturales y sintéticos jóvenes y envejecidos). En su preparación este producto debe aditivarse con acetato de etilo (volumen de acetato de etilo $=$ (Volumen total deseado x 9) / 100; Volumen de recubrimiento polar de Nanorestore Cleaning ${ }^{\circledR}=$ Volumen total deseado - Volumen de acetato de etilo). CSGI. "Nanorestore Cleaning ${ }^{\circledR}$. Technical Sheet". [En línea]. Revised 5/3/19. Copyright @ CSGI 2015. Sesto Fiorentino, Italy. <http://www.csgi.unifi.it/products/downloads/ cleaning ts eng.pdf $>$. [Consulta: 24/05/20]. pp. 1-7.

[8] La "Comisión International d'Eclairage" (CIE) de 1976 recomienda las coordenadas de color; $L^{*}$ para la luminosidad, $a^{*}$ para el eje rojo/verde y $b^{*}$ para el eje azul/amarillo. Fuente: A. S. Ortiz, A. S. Ledesma, and S. M. Boró, "Evaluación de diferencias de color en tres materiales contemporáneos para la reintegración cromática de bienes culturales," Opt. Pura y Apl., vol. 43, no. 2, pp. 141-151, 2010.

[9] Para la retirada de la suciedad superficial se emplearon brochas suaves de pelo de cabra y un aspirador. Tras la aspiración se realizó una segunda limpieza en seco con goma Akapad ${ }^{\circledR}$ Soft en todo el anverso y goma Mars Staedler ${ }^{\circledast}$ en la limpieza de las huellas dactilares de los márgenes. Por otra parte, en la eliminación de diversos cercos por escorrentía de agua situados en el borde superior de uno de los dípticos se utilizaron geles de agar agar con 1\% TAC (pH 8 y conductividad $4.000 \mu \mathrm{S} / \mathrm{cm}$ ).

[10] Después de finalizar la limpieza, fue necesario aplicar distintos retoques de reintegración cromática con motivo de homogeneizar estéticamente el fondo del díptico derecho, pues no se alcanzó una limpieza homogénea al 100\%. Es decir, puntualmente quedaron algunos matices y sombras muy ligeras. Estas fueron integradas estéticamente empleando pasteles Rembrandt ${ }^{\circledR}$ de Royal Talens, los cuales fueron rayados y aplicados a pincel sobre la tela sin color, tratándose de un sistema de reintegración reversible autorizado por el autor.

\section{Referencias}

AENOR (1994). "Pinturas y barnices. Colorimetría". Norma Española UNE 48-073-94, vol. Parte 3. 1-8.

AENOR (1999). "Pinturas y barnices. Determinación del brillo especular de películas de pintura no metálicas a 200,600 y $850^{\prime \prime}$. Norma Española UNE-EN ISO 2813.

AENOR (2005). "Pinturas y barnices. Envejecimiento natural de recubrimientos. Exposición y evaluación". Norma Española UNEEN ISO 2810, vol. Parte 3. 1-8.

ASTM (2010). "Standard Practices for Resistance of Adhesives to Cyclic Laboratory Aging Conditions". D1183-03. 1-3.

ANTUÑEZ, V., ORTIZ, P., MARTÍN, J. M., GÓMEZ MORÓN, A., ORTIZ, R. (2012). "Evaluación de Métodos de Limpieza de Graffiti en Mármol". Macla. Rev. la Soc. Española Mineral. 16(4): 68-69. 
AHEDO, C. y CANTOSO. (2014). “Nuevos emulsionantes poliacrílicos en la formulación de sistemas acuosos de limpieza: Pemulen TM TR-2". Informes y Trabajos, № 10. IPCE-MCD. Madrid: IPCE. 166-186.

ARTE Y MEMORIA. "Catálogo Arte y Memoria: Rayón". [En línea]. Barcelona. https://www.arteymemoria.com/docs/cataleg spain. pdf [Consulta: 24/05/20]. 26.

ORTIZ, A. S., LEDESMA, A. S. y BORÓ, S. M.(2010). “Evaluación de diferencias de color en tres materiales contemporáneos para la reintegración cromática de bienes culturales," Opt. Pura y Apl., 43( 2): 141-151.

CREMONESI, P. y SIGNORINI, E. (2012). “Un approccio alla pulitura dei dipinti mobili". II Prato.

CREMONESI, P. (2016). “Proprietà ed esempi di utilizzo di materiali siliconici nel restauro di manufatti artistici". II Prato.

CSGI. "Nanorestore Cleaning ${ }^{\oplus}$. Technical Sheet". [En línea]. Revised 5/3/19. Copyright @ CSGI 2015. Sesto Fiorentino, Italy. http://www. csgi.unifi.it/products/downloads/cleaning ts eng.pdf [Consulta: 24/05/20]. 1-7.

CSGI. "Nanorestore Gel ${ }^{\otimes}$ Dry. Technical Sheet". [En línea]. Revised 5/3/19. Copyright $\odot$ CSGI 2015. Sesto Fiorentino, Italy. http://www. csgi.unifi.it/products/downloads/geldry ts eng.pdf. [Consulta: 24/05/20]. 1-9.

CSGI. "NANORESTORE GEL ${ }^{\circledR}$ Solutions for conservation of Cultural Heritage" 2015. [En línea]. Available: http://www.csgi.unifi.it/ products/gel.html. [Consulta: 28/07/2018].

SANTABARBARA MORERA, C. (2015) “La teoría de la conservación de Hiltrud Schinzel. Una alternativa a la teoría de la restauración de Cesare Brandi", Conservación de Arte Contemporáneo, 15a Jornada, Museo Reina Sofía, Madrid, 11-18.

CTS. "Relación técnica. Espesantes". [En línea]. CCopyright C.T.S. España S.L. https://shop-espana.ctseurope.com/ documentacioncts/fichastecnicasweb2018/3.1 disolventes2016/ relaciones-brochure/espesantes.pdf. [Consulta: 24/05/20]. 6-7.

CTS. "Velvesil Plus. Descripción del producto". [En línea]. https:// www.ctseurope.com/es/scheda-prodotto.php?id=4001. [Consulta: 24/05/20].

CTS. "Gellano Kelcogel ${ }^{\oplus " . ~ \odot C o p y r i g h t ~ C . T . S . ~ E s p a n ̃ a ~ S . L . ~[E n ~ l i ́ n e a] . ~}$ https://shop-espana.ctseurope.com/documentacioncts/fichast ecnicasweb2018/3.1disolventes2016/gellanokelocogelesp.pdf. [Consulta: 24/05/20].

DOHERTI, T. y STAVROUDIS, C. (2012). “Desarrollando sistemas de limpieza para pinturas sensibles al agua mediante ajuste del $\mathrm{pH}$ y la conductividad". Conservación de Arte Contemporáneo. 13a Jornada. Madrid: MNCARS. 39-48.

GÁMIZ RIVAS, R. (2014). “Estudio teórico-práctico de diferentes sistemas para la reducción y eliminación de barnices naturales en las obras de arte pictóricas". Unicum. L'Escola Superior de Conservació i Restauració de Béns Culturals de Catalunya, 14: 239-247.

GUTIERREZ. F. (1997). “Aplicación de la espectrometría infrarroja al análisis químico de los bienes culturales". PH Boletín, 18: 56-60.

K. MINOLTA. “Espectrofotómetro CM-700d". [En línea]. Available: http://sensing.konicaminolta.com.mx/products/cm-700dspectrophotometer/

MECKLENBURG, M., CHAROLA, Ey KOESTLER, R. (2013). New Insights into the Cleaning of Paintings: Proceedings from the Cleaning 2010 International Conference, Universidad Politécnica de Valencia and Museum Conservation Institute. Washington D. C.: Smithsonian Institution Scholarly Press.

MIRKA. "Abranet ACE". [En línea]. C) 2020 Mirka Ltd. https://www. mirka.com/es/ABRANET-ACE-ACO/ [Consulta: 24/05/20].

MONTESINOS, R. (2013). "Especificación cromática de gamas de colores usadas en la industria del calzado," Universidad de Alicante $1-120$.

ORTIZ, P., ANTUÑEZ, V., ORTIZ, R., MARTIN, J. M., GÓMEZ, M. A., HORTAL, A. R., MARTINEZ HAYA, B. (2013). "Comparative study of pulsed laser cleaning applied to weathered marble surfaces". Applied Surface Science, 283: 193-201.

PLOEGER, R. y CHIANTORE, O. "Caracterization and Stability Issues of Artist's Alkyd Paints". New Insights into the Cleaning of Paintings: Proceedings from the Cleaning 2010 International Conference, Universidad Politécnica de Valencia and Museum Conservation Institute. Washington D. C.: Smithsonian Institution Scholarly Press. 8995.

TEMPEST, H., BURNSTOCK, A., SALTMARSH, P. y VAN DEN BERG, K. "Sensitivity of Oil Surfaces to Aqueous and Other Solvents". New Insights into the Cleaning of Paintings: Proceedings from the Cleaning 2010 International Conference, Universidad Politécnica de Valencia and Museum Conservation Institute. Washington D. C.: Smithsonian Institution Scholarly Press. 107-114.

SKOOG, D. A., JAMES, H. F. y CROUCH, S. R. (2008). Principios de análisis instrumental. Sexta edic. CENAGE Learning.

VILLEGAS SÁNCHEZ, R. (2002). "La microscopía electrónica de barrido para el estudio del patrimonio histórico". PH. 117-122.

VV.AA. (1972). Catálogo de la exposición "Arte Actual Valenciano", realizada en abril-mayo de 1972 en el Museo de ArteContemporáneo de Sevilla. Museo de Arte Contemporáneo de Sevilla, Arte actual valenciano, exposición abril-mayo 1972. Sevilla, MACS. 1972.

WOLBERS, R. (2010). Cleaning Painted Surfaces: Aquous Methods. London: Archetype Publications.

X-RITE, I. "Elcometer 407 Statistical Glossmeter," 2011. [En línea]. Available: http://www.kamado.pl/doc/110-336 elcometer 407 en.pdf. 


\section{Autor/es}

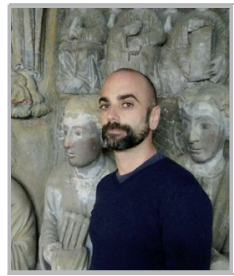

\section{Livio Ferrazza}

livio.ferrazza@gmail.com

Colaborador externo del Institut Valencià de Conservació i Restauració (IVCR+i)

Livio Ferrazza es Doctor en Química y Diplomado en Ciencias para la conservación de bienes culturales por la Universidad "La Sapienza" de Roma. Desde 2007 colabora con el Laboratorio de Materiales del Instituto Valenciano de Conservación, Restauración e Investigación (IVCR+i), trabajando en los análisis de laboratorio de muestras de bienes culturales tales como pintura de caballete, pintura sobre tabla, pintura mural, piedra, textil, papel, metal, etc. Ha participado en numerosas líneas de investigación con una destacada trayectoria en la evaluación tratamientos de estabilización y de limpieza de superficies policromadas, soporte pétreo y pinturas murales. Desde 2009 colabora con esta institución en los estudios analíticos y evaluación de los tratamientos de restauración en las pinturas murales de la Casa de Ariadna en Pompeya, en la Portada de Los Apóstoles de la Basílica Arciprestal de Morella (Castellón) o en la caracterización de materiales y evaluación de los tratamientos de limpieza en la pintura gótica valenciana como en el caso de la predela del Centenar de la Ploma del Victoria and Albert Museum de Londres. En 2014 recibe la beca Fundación Andrew W. Mellon colaborando con el Instituto del Patrimonio Cultural de España (IPCE) de Madrid en la evaluación de la eficacia y del riesgo asociado a los diferentes sistemas de estabilización y de limpieza de la policromía sobre piedra en el Pórtico de la Gloria de la Catedral de Santiago de Compostela. Ha colaborado en la línea de investigación del proyecto PNIC2015-05: Protocolo de evaluación del riesgo para la intervención en conjuntos escultóricos de piedra policromada, a través del cual se ha desarrollado un protocolo para la evaluación del riesgo y la eficacia en los diferentes tratamientos a emplear (limpieza, desbiotización, fijación, consolidación). Su participación en numerosos estudios químicos-analíticos aplicados a los bienes culturales han sido publicados y presentados en revistas y congresos especializados.

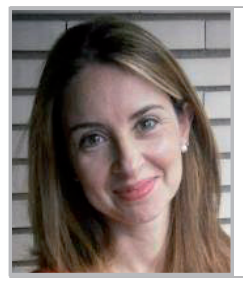

\section{Mayte Pastor Valls}

tpastor@dipcas.es

Técnico. Servicio de Restauración de la Diputación de Castellón

Mayte Pastor es doctora por la Universidad Politécnica de Valencia, con la tesis Estudio de sistemas y tratamientos de estabilización en pintura contemporánea. Criterios y metodologías de intervención (calificada Cum Laude en 2013, premio extraordinario UPV 2016). Es además, Licenciada en Humanidades por la Universitat Jaume I, Diplomada y Título superior en Conservación y Restauración de Bienes Culturales en la Especialidad de Pintura por la Escola Superior de Conservació i Restauració de Béns Culturals de Catalunya y Máster en Diagnóstico del Estado de Conservación del Patrimonio Histórico por la Universidad Pablo de Olavide de Sevilla.
Actualmente desarrolla su trabajo como técnico superior en conservación restauración de arte contemporáneo en el Servicio de Restauración de la Diputación de Castellón. Dentro de esta especialidad ha trabajado como contratada y freelance para el Museu d'Art Contemporani de Vilafamés Vicente Aguilera Cerni (MACVAC), Instituto Valenciano de Conservación Restauración e Investigación (IVCR+i) y Colección Martínez GuerricabeitiaUniversitat de València, junto a diversas colecciones privadas, etc. En 2015 obtuvo la beca postdoctoral Mellon Foundation Programa Catedral de Santiago, realizando una investigación sobre la estabilidad y viabilidad de polímeros consolidantes y adhesivos aplicados a las policromías del Pórtico de la Gloria y colaborando posteriormente y de forma puntual con el proyecto PNIC2015-05: Protocolo de evaluación del riesgo para la intervención en conjuntos escultóricos de piedra policromada. Participó en el proyecto “Investigación, producción y comercialización de la vejiga de esturión producida en Riofrío (Granada) de la Universidad de Sevilla y bajo la dirección del IVCR+i, formó parte del equipo que realizó los estudios previos de limpieza y consolidación de la portada policromada de la Iglesia Arciprestal de Santa María la Mayor de Morella (Castellón) s. XIV, restaurada recientemente.

Maite Ciganda Azcarate
mciganda.escrbca@gmail.com
Conservación y Restauración de Bienes
Culturales por la ESCYRA

Maite Ciganda Azcarate está graduada en Conservación y Restauración de Bienes Culturales por la ESCYRA de Huesca con la especialidad en pintura y en 2018 obtiene la titulación de Máster en Diagnóstico del estado de conservación por la Universidad Pablo de Olavide de Sevilla. Actualmente colabora con la empresa italiana Diagnostica per il Restauro e la Conservazione en la difusión y captación de clientes, toma de muestras, análisis de resultados y redacción de informes. Ha participado en las Jornadas de Restauración anuales organizadas por ACYRA y la ESCYRA como traductora de la restauradora Enrica Boschetti durante su ponencia y workshop.
Artículo enviado el 04/05/2020
Artículo aceptado el 18/11/2020

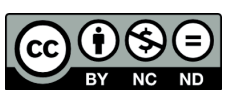

https://doi.org/10.37558/gec.v18i1.765 